\title{
Agent-backgrounding in Catalan Sign Language (LSC)
}

Gemma Barberà, ${ }^{\mathrm{a}}$ Patricia Cabredo Hofherr, ${ }^{\mathrm{b}}$ \& Josep Quer ${ }^{\mathrm{a}, \mathrm{c}}$

${ }^{\mathrm{a} U n i v e r s i t a t}$ Pompeu Fabra; ${ }^{\mathrm{b}}$ CNRS UMR 7023/Université Paris 8 (UPL); ${ }^{\mathrm{c} I C R E A}$

This paper examines backgrounding strategies for human agents in Catalan Sign Language, that is, constructions featuring human agents that are non-referential. We identify and analyze four types of agent-backgrounding strategies, namely subjectless constructions, indefinite pronouns, the impersonal axis and general nouns. Extending on previous work, we offer a description and a semantico-pragmatic analysis of each construction.

Keywords: Backgrounding, Catalan Sign Language (LSC), impersonal axis, indefinite pronoun, impersonal reference

\section{Introduction}

The present paper examines backgrounding strategies for human agents in Catalan Sign Language (llengua de signes catalana, LSC), that is, constructions featuring human agents that are non-referential. We used the Jena-Paris R-Impersonals questionnaire (see Section 5 of the Introduction) to elicit a range of strategies used in LSC in contexts that are crosslinguistically typical for pronouns and noun phrases that background human agents. Building on previous work, we focus on four types of agent-backgrounding strategies, more closely: empty subject constructions, indefinite pronouns, the impersonal axis and lexical subjects.

\section{Methodology}


The data used in this study is based on elicitation sessions from two native deaf signers (one woman and one man), in their late 40s living in the area of Barcelona. We used the Rimpersonals questionnaire, in written language, as a starting point to elicit a representative range of possible constructions used for agent-backgrounding. The questionnaire probes a number of contrasts that are known to be relevant cross-linguistically in the distribution of different impersonal human subjects. In order to minimize transfer effects from the questionnaire language (written Spanish) to the language under examination (LSC), we provided a wider context for each example and proceeded using the following four steps. In step 1 we provided the context in LSC. In step 2 we showed the target sentence in written language. In step 3 we asked the informants to provide the most natural way of rendering the target sentence and recorded the possible options. In follow-up sessions (step 4) we discussed the recorded signed videos. The sentences were modified when needed, and new examples with different strategies were added and discussed. In step 2 it was made clear to the informants that the target written sentence should be seen as a metalanguage (Matthewson 2004): the instruction to the informants was to consider the target sentence as an input from which they should aim to find the most natural equivalent in LSC for the given context. It was explained that they did not need to use the same pronoun/noun phrase as in the written version. The follow-up sessions in step 4 are crucial, as they allow detaching the LSC examples from the written questionnaire in Spanish to control for transfer of Spanish structures into the LSC examples. The final output for the present study came out of the discussions of the signed versions of the sentences after this final step.

Based on the questionnaire we elicited the following strategies used for agentbackgrounding/unknown human agents:

(1) Nominal strategies

a. No lexical subject

b. Lexical subjects

a. Generalised noun: PERSON $\mathrm{up}^{+++}$

b. Determiner + generalised noun: $\mathrm{ONE}_{\mathrm{up}} \mathrm{PERSON}_{\mathrm{up}}$

c. Pronouns

a. Indefinite pronoun: $\mathrm{ONE}_{\mathrm{up}}$ 'one/someone'

b. Indefinite pronoun: $\mathrm{WHO}^{\wedge} \mathrm{SOME}_{\text {up }}$ 'someone'

c. $3^{\text {rd }}$ person plural: IX3pl 'they'

(2) Inflectional strategies

a. Impersonal axis

b. Agreement verbs agreeing with an empty high locus 
In what follows we discuss four agent-backgrounding strategies in LSC used in R-impersonal contexts in more detail: (i) constructions without a lexical subject (Section 3.1), (ii) two indefinite pronouns (Section 3.2), (iii) the impersonal axis (Section 3.3) and (iv) lexical subjects (Section 3.4).

\subsection{No lexical subject}

Barberà \& Cabredo Hofherr (2017a) show that there are at least two distinct constructions without a lexical subject in LSC. In the "high locus construction" an empty subject combines with an agreement verb that shows agreement with an empty locus in a high location. In the "non-agreeing central construction" a plain verb is articulated without a lexical subject in a central location.

The two constructions are clearly distinct. The high locus construction forces a human interpretation of the agent while the non-agreeing central construction also allows anticausative readings and readings with inanimate causes (Barberà \& Cabredo Hofherr 2017a: 779-780, henceforth B\&CH). ${ }^{1}$

\section{(3) High locus construction}

POT FLOWER BREAK 3 up.

'They/someone broke the vase.' (human agent only)

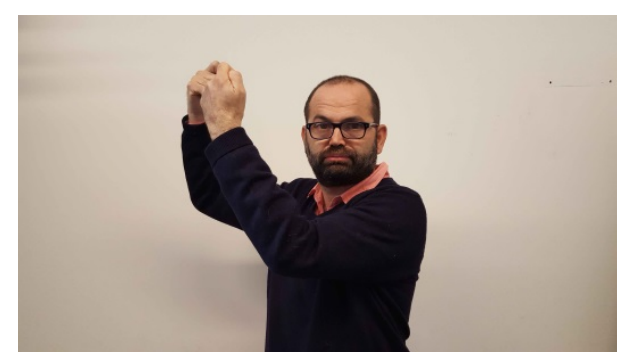

Figure 1. High locus agreeing construction featuring the verb BREAK3 $\mathbf{u p}_{\text {up }}$ (B\&CH 2017a: 779-780, ex. 33 \& Fig. 9)

\footnotetext{
1 This article follows the usual glossing conventions in the sign language literature, representing manual signs by the capitalized word corresponding to the translation of the sign. The abbreviations used in the glosses are the following (\# is a placeholder for the loci in signing space corresponding to 1st, 2nd and 3rd person referents): IX\# (index pointing sign); \#-VERB-\# (verb agreeing with subject and object); sub-indices mark localisation in signing space: up (up); c (centre); lower indexed letters (a...) mark coreference relations; CL for classifier construction, are followed by the kind of classifier (ent for entity classifier) and a rough meaning description. Reduplication of signs is indicated by +++ .
} 


\section{(4) Non-agreeing central construction}

POT FLOWER BREAK .

'The vase broke.'

(i) anticausative

(ii) inanimate cause

(iii) human agent

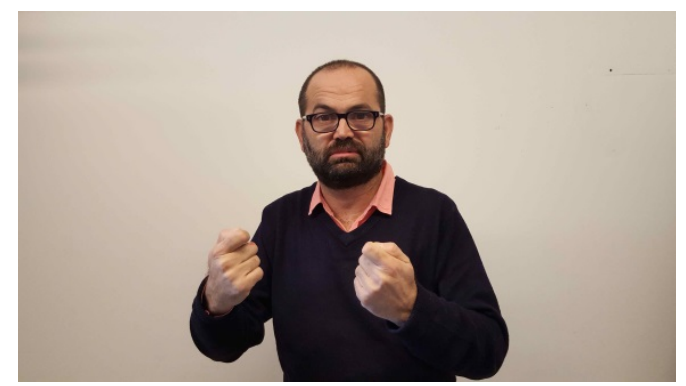

Figure 2. Non agreeing central construction featuring the verb BREAK $_{\mathbf{c}}(\mathrm{B} \& \mathrm{CH}$ 2017a: 779-780, ex. 32 \& Fig. 8)

In LSC, the high locus construction is a transitive construction and the null subject can therefore be analysed as an R-impersonal strategy. The non-agreeing central construction, in contrast, is not an R-impersonal strategy but an argument reduction process more akin to a middle construction (in Keenan \& Dryers's (2007) sense), allowing different types of agents and anticausative interpretations. For a detailed discussion of the syntactic properties of these two subject-less constructions see B\&CH (2017a: 778-794).

$\mathrm{B} \& \mathrm{CH}(2017 \mathrm{a})$ analyse the high locus construction as an R-impersonal strategy with the high empty locus corresponding to a null R-impersonal subject. Here, we examine the distribution of the high locus construction across the range of contexts given in the Rimpersonals questionnaire (see the Introduction to this volume). The most common types of context available for the high locus agreeing construction are vague existential contexts (Q2), i.e., episodic contexts lacking temporal specification (existential quantification over a time interval):

3up TELL 1 ONE THEME SLEEP CAN'T-SLEEP. (video)

'Someone told me a story which didn't allow me to sleep.'

As shown by the two examples below the high locus construction in LSC also appears in anchored existential contexts (Q1: situations anchored to a specific point in time and space). The example in (6) includes a backwards agreeing verb like STEAL (moving from object to subject), and the example in (7) includes a regular agreeing verb like BRING (moving from subject to object). 
(6) YESTERDAY UNIVERSITY BUILDING IN-FRONT BIKE IX STEAL $_{3}$ up.

'Yesterday they stole my bike in front of the university building.'

(7) UPF MAIL 3upBRING TIME 8 MORNING.

'At UPF they bring the mail at 8 am.'

Corporate contexts (Q6 with designated subjects associated with the predicate) are also available for the high locus construction. The example in (8) features the regular agreeing verb TELL (moving from subject to object), and the example in (9) features the backwards agreeing verb TAKE (moving from object to subject).

(8) 3upTELL1 LIE MORE. IX 3 up I-V-A INCREASE REASON FOR INFORM THERE-IS SHOW.

'They told another lie and this allowed them to justify the increase of the VAT.'

(9) CLOTHES SECOND-HAND 3up TAKE+++. (VIDEO)

'They have taken away the second-hand clothes.'

Finally, locative universal contexts (Q7 characterized by the presence of a locative restricting the referent of the subject) are also available for the high locus construction. In (10) the backwards agreeing verb UNDERSTAND shows agreement with an empty locus in a high location.

(10) SPAIN IX 3 3up.a IX I $_{2}$ UNDERSTAND-NOT 3 3up.a.

'In Spain, they don't understand us.'

\subsection{Indefinite pronouns}

Indefinite pronouns are one of the most frequent strategies to convey R-Impersonal contexts in LSC (Barberà \& Quer 2013). In particular, the pronouns $\mathrm{WHO}^{\wedge} \mathrm{SOME}_{\text {up }}$ and $\mathrm{ONE}_{\text {up }}$ convey epistemic non-specificity and are both articulated in a high locus. The two indefinite pronouns co-occur with particular non-manuals, illustrated in Fig. 3 and Fig. 4, that include sucking the cheeks in and pulling the mouth ends down, sometimes combined with a shrug (Barberà 2016). 


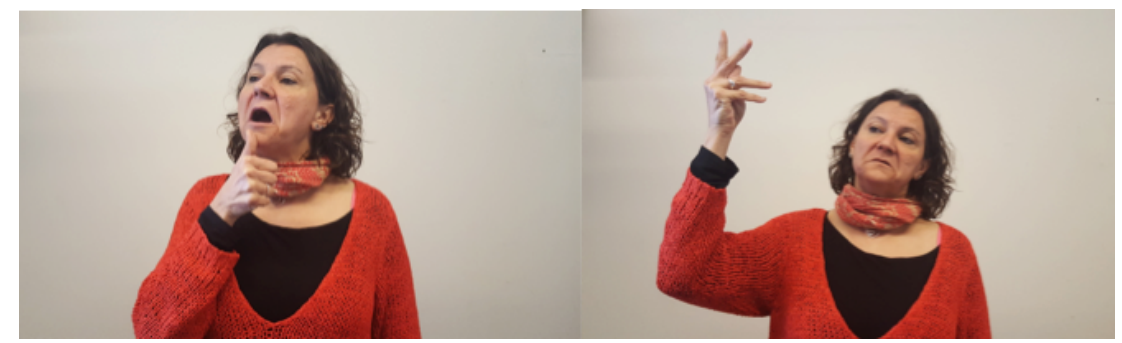

Figure 3. Indefinite pronoun $\mathrm{WHO}^{\wedge} \mathrm{SOME}_{\mathrm{up}}$

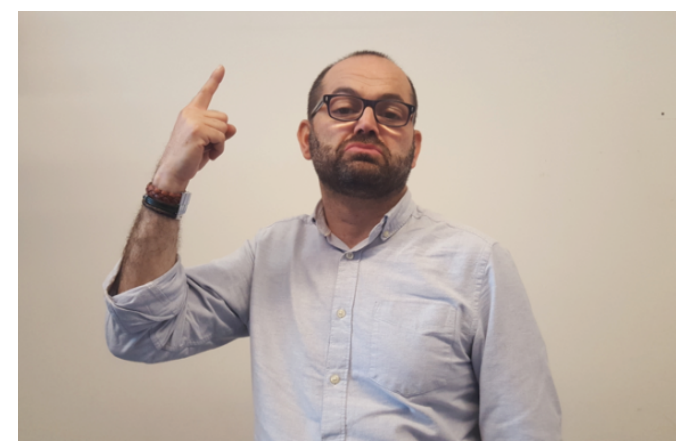

Figure 4. Indefinite pronoun $\mathrm{ONE}_{\mathrm{up}}$

The most common environments in which both pronouns may be found are locative universals (Q7), indirect evidential existentials (Q3), vague and anchored existentials (Q2 and $\mathrm{Q} 1)$, conditionals (Q11) and unrestricted universal contexts (Q9 and Q10). In fact, $\mathrm{WHO}^{\wedge} \mathrm{SOME}_{\text {up }}$ and $\mathrm{ONE}_{\text {up }}$ are not distinguished by the type of contexts in which they are found, but rather by their intrinsic semantic properties.

Both pronouns pattern with indefinite pronouns, not with existential readings of dedicated R-impersonal pronouns like French on ((13) and (14)), as they do not allow generic readings (11) or corporate readings (12) (see Sections 4.1 and 4.2 in $\mathrm{B} \& \mathrm{CH} 2017 \mathrm{~b}$ : 94-99).

(11) a. LLEIDA ONE $\mathrm{up}_{\mathrm{p}}$ SNAIL EAT.

b. LLEIDA WHO ${ }^{\wedge} \mathrm{SOME}_{\text {up }}$ SNAIL EAT.

'In Lleida, there is someone who eats snails.'

$\rightarrow$ not generalizing over people associated with Lleida

(B\&CH 2017b:95, ex 14)

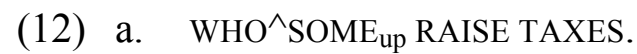

b. ONE $\mathrm{Op}_{\text {up }}$ RASE TAXES.

'Someone raised taxes.'

(B\&CH 2017b:95, ex 13)

(13) À Lleida on mange des escargots. (French) in Lleida on eats DET.INDEF snails 'In Lleida, people eat snails.' 
$\rightarrow$ generalizing over people associated with Lleida

(14) On a augmenté les impôts.

(French)

on has raised DET taxes

$\rightarrow$ generalizing over the group of people associated with raising taxes

The pronouns $\mathrm{WHO}^{\wedge} \mathrm{SOME}_{\text {up }}$ and $\mathrm{ONE}_{\mathrm{up}}$ differ with respect to their specificity profile. As shown in detail by Farkas (2002) and von Heusinger (2002) semantic specificity encompasses a range of diverse semantic properties. Following Farkas (2002) we distinguish epistemic, scopal and partitive specificity. Both $\mathrm{WHO}^{\wedge} \mathrm{SOME}_{\text {up }}$ and $\mathrm{ONE}_{\text {up }}$ are epistemically non-specific indefinite pronouns: the referent has to be unknown to both the signer and the addressee (B\&CH 2017b: 94).

(15) a. ONE up HOUSE ENTER STEAL 3 up. (video)

b. $\mathrm{WHO}^{\wedge} \mathrm{SOME}_{\text {up }} \mathrm{HOUSE}$ ENTER STEAL 3 up. (video)

'Someone broke into the house.'

With respect to scopal and partitive specificity, the two pronouns differ. $\mathrm{WHO}^{\wedge} \mathrm{SOME}_{\text {up }}$ is interpreted as scopally non-specific, co-varying with adverbs and event pluralities (16a), while $\mathrm{ONE}_{\text {up }}$ is scopally specific: the referent of $\mathrm{ONE}_{\mathrm{up}}$ is constant across the event-pluralities (16b) (see sections 4.3 and 5.3 in $\mathrm{B} \& \mathrm{CH} 2017 \mathrm{~b}$ ).

(16) a. BUILDING IX POSS OFFICE DANGER. WHO^${ }^{\wedge}$ SOME $_{\text {up }}$ STEAL $_{3 \text { up MONEY. }}$

'The building of my office is very dangerous. They (always) steal money.'

$\rightarrow$ the stealing event has happened many times, potentially different agents

b. BUILDING IX DANGER. IX 1 POSS OFFICE ONE $_{\text {up STEAL }}$ 3up MONEY.

'The building of my office is very dangerous. Someone stole/steals money.'

(i) single referent for the agent and the stealing event is punctual

(ii) single referent for the agent and stealing event is iterated (same unknown agent in multiple events)

(B\&CH 2017b: 101, ex 42a/b)

The two pronouns also differ with respect to partitivity: while the referent of $\mathrm{ONE}_{\mathrm{up}}$ is interpreted partitively (17b), as belonging to a salient group, $\mathrm{WHO}^{\wedge} \mathrm{SOME}_{\text {up }}$ does not impose a partitive interpretation (17a) (Section 5.4 in B\&CH 2017b).

(17) BUILDING IX FIRE FIREMEN ARRIVE.

'The building was on fire. The firemen arrived.'

a. $\mathrm{WHO}^{\wedge} \mathrm{SOME}_{\text {up }} \mathrm{CL}_{\text {ent }}$ 'go up roof'. 
'Someone (fireman or person from the street) went onto the roof.'

b. $\mathrm{ONE}_{\text {up }} \mathrm{CL}_{\mathrm{ent}}$ 'go up roof'.

'One (of the firemen) went onto the roof.'

(B\&CH 2017b: 101-102, ex 43a/b)

$\mathrm{WHO}^{\wedge} \mathrm{SOME}_{\text {up }}$ and $\mathrm{ONE}_{\text {up }}$ pattern with indefinite pronouns like English someone as they do not allow generic interpretations in simple sentences (such as unrestricted universal contexts and locative universal contexts) and do not give rise to corporate readings in corporate contexts. Like indefinite pronouns, they allow generalizing readings in if/when-clauses:

(18) ONEUP MOMENT HOSPITAL GO, ALWAYS THINK RESULT WORST. (video)

'When someonej is admitted to the hospital, s/he j always fears the worst results.'

(19) $\mathrm{WHO}^{\wedge} \mathrm{SOME}_{\text {up }}$ EXAM DONE, LEAVE CAN.

'When someone finishes the exam s/he can leave. (B\&CH 2017b: 99, ex 32)

Summarising, we have provided arguments that show that $\mathrm{WHO}^{\wedge} \mathrm{SOME}_{\text {up }}$ and $\mathrm{ONE}_{\text {up }}$ are indefinite pronouns that differ with respect to their specificity profile: while both are epistemically non-specific, $\mathrm{ONE}_{\mathrm{up}}$ is interpreted as scopally and partitively specific, while $\mathrm{WHO}^{\wedge} \mathrm{SOME}_{\mathrm{up}}$ is neutral with respect to scopal and partitive specificity (for a more detailed discussion see B\&CH 2017b).

\subsection{Impersonal axis}

The use of the impersonal axis for backgrounded human reference in LSC was first described in Barberà \& Quer (2013). The impersonal axis marks the lack of referential encoding of the discourse referents through locations established in signing space by means of agreeing verbs. The axis goes from a spatial location established between $1^{\text {st }}$ and $3^{\text {rd }}$ person to a location established between $2^{\text {nd }}$ and $3^{\text {rd }}$ person location (Figure 5).

(20) IF $1 / 3 \mathrm{INSULT}_{2 / 3}$, IGNORE.

'If they insult you imp, you'd better ignore them.'

(Barberà \& Quer 2013: 249, ex. 16)
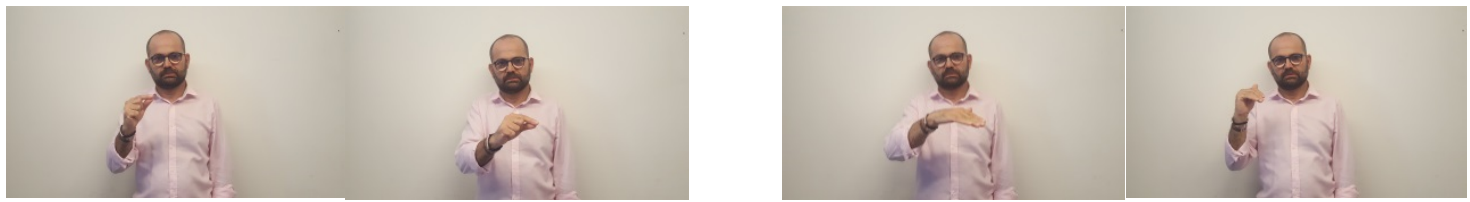
Figure 5. Impersonal axis

In the impersonal axis structure both arguments of the verb are two non-specified arguments and this is marked in the diagonal movement of the agreeing verb and in the initial and final locations. The two examples below show instances of R-impersonal objects ((21) and (22)). The contexts of the two sentences are general instructions given to students in a generalizing context. Because the audience of the two sentences are students they cannot yet get to the examination stage (they first need to get the final degree). Therefore, the two sentences cannot trigger a deictic meaning. Both regular and backwards agreeing verbs may be inserted in a structure where the impersonal axis is used. As shown below, a regular agreeing verb like CALL (21) and a backwards verb like SUMMON (22) display an inverse pattern of path movement: while the regular verb moves from an unspecified subject location to an unspecified object location (22), the backwards verb moves from the unspecified object location to the unspecified subject location.

EXAMINATION EXAM 1/3 CALL $/ 3_{\mathbf{3}}$, SURE 2/3 SELECT $_{1 / 3}$ WORK. (video)

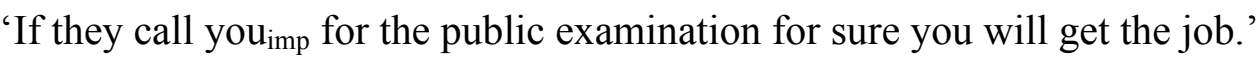

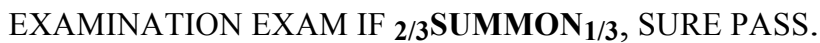

'If they summon you ${ }_{i m p}$ for the public examination for sure you will get the job.'

Non-manual marking is a crucial component in the articulation of the impersonal axis. Examples with the impersonal axis (21) and (22) are expressed with a tremoring side movement of the head starting before the articulation of the manual sign, a darting eyegaze non-aligned with the final end-point of the verb and sometimes with a lax articulation of the verb (example (21) corresponding to Figure 6).

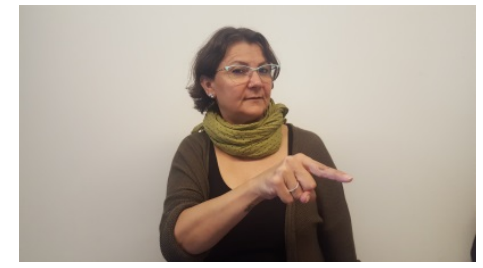

Figure 6. ${ }_{1 / 3} \mathrm{CALL}_{2 / 3}$, impersonal axis with impersonal reading

The impersonal reading found with the impersonal axis contrasts with (23), which is an instance of an episodic context with a deictic use of the $2^{\text {nd }}$ person in which instructions are given to a particular individual. The deictic reading is triggered by the location of the object argument in the $2^{\text {nd }}$ person spatial location and the non-manual marking includes a fixed 
eyegaze towards the spatial location assigned for the $2^{\text {nd }}$ person and an alignment between the direction of the eyegaze and the final end point of the verb (see Fig. 7 corresponding to (23)).

EXAMINATION EXAM ${ }_{3}$ CALL $_{2}$, SURE $_{2} \mathrm{SELECT}_{3}$ WORK.

'If they call you for the public examination for sure you will get the job.'

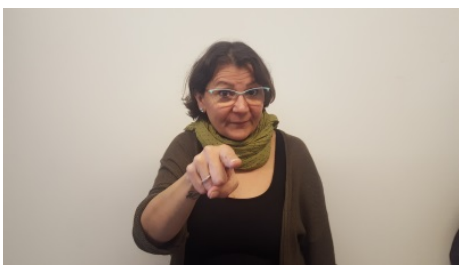

Figure 7. ${ }_{3} \mathrm{CALL}_{2}$, deictic reading

That a spatial location is established between the $1 / 3$ and the $2 / 3$ locations is shown by the fact that a coreferential pronoun directed to the same 1/3 location is found in the subsequent sentence in (24). Agreeing verbs directed towards the same location use it for coreference (25).

IF $1 / 3 \mathrm{a}$ INSULT $2 / 3$, BETTER IGNORE. REALITY ILL-MANNERED IX $\mathbf{3 a}$. (video)

'If they insult you $\mathrm{imp}_{\mathrm{im}}$ you better ignore them. They are the ones who are ill-mannered, indeed.'

\section{IF ${ }_{1 / 3 a}$ INSULT EXPEL $1 / 3 a$.}

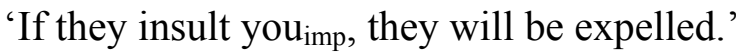

The impersonal axis in LSC is mainly found in vague existential contexts and in conditional contexts with a generic habitual reading and it is featured by an if/when structure. ${ }^{2}$ As shown in example (26) the if/when structure of the impersonal axis is also found with locative universals in generic/habitual contexts where the locative expression functions as part of the restriction of the generic quantification ('when you are a new student in this university).

\section{(26)}

UNIVERSITY IX STUDENT BEGINNER ARRIVE, ALWAYS $1 / 3 \mathrm{MOCK}_{2 / 3}$.

'In this university, when you are a new student, you are always mocked.'

\footnotetext{
2 The special conditions in which the impersonal axis is found show the particular properties of the structure, which are akin to the special use of personal pronouns used with an impersonal reading. In the elicited data no instance of $1^{\text {st }}$ person singular has been found with an impersonal use. However, in naturalistic data and more concretely the Aesop fables narrated in LSC we found some examples of $1^{\text {st }}$ person singular pronouns with an impersonal reading, which always occurred in a conditional context (Barberà \& Costello 2017). As for the $2^{\text {nd }}$ person pronoun, while LSE and TID (Costello 2015 and Kelepir et al. this volume) allow a lax articulation form used with an impersonal reading as long as it is inserted in a conditional context, no equivalent has been found so far in LSC in elicited or naturalistic data.
} 


\subsection{Lexical subjects}

Lexical subjects are another frequent strategy when conveying agent-backgrounding. Here we focus on two different constructions signalled by two different lexical elements: on the one hand, the generalised noun PERSON $\mathrm{up}^{+++}$articulated as the reduplication of the sign PERSON localised in a high locus; and on the other, the noun phrase formed by the indefinite determiner $\mathrm{ONE}_{\text {up }}$ and the generalised noun PERSON $\mathrm{up}$ in its singular form, both associated with a high locus.

The generalised noun PERSON $\mathrm{up}^{+++}$is available mainly in locative universal contexts (27) and in unrestricted universal contexts (28), as shown below. While in (27) the verb TALK agrees with the high locus, in (28) the verb STEAL agrees with the central locus where the classifier predicate for "people walking" has been localised.

IX BALEARIC-ISLANDS PERSON up $^{+++}$TALK $_{\text {up }}$ CATALAN. (video)

'In the Balearic islands, they speak in Catalan.'

SAY AREA BARCELONA PERSON ${ }_{\text {up }}+++$ CL $_{\text {ent }}$ 'person-walk ${ }_{\mathrm{c}}$ ' WATCH-OUT STEAL $\mathrm{W}_{\mathrm{C}}+++$.

'They say that in Barcelona, when people walk about, they watch out for stealing.'

The combination of indefinite determiner and generalised noun, $\mathrm{ONE}_{\mathrm{up}}$ PERSON $\mathrm{up}$, is mainly available in specific and vague existential contexts, inferred existentials, unrestricted universal contexts, conditionals, and when-contexts. (29) shows a conditional and generic context in which the determiner and the generalised noun trigger a partitive meaning ('one of the persons playing in the quiz game'). Example (30) shows an unrestricted universal context. The general noun PERSON ${ }_{\text {up }}$ is a functional element, rather than a common noun. Replacing PERSON $_{\text {up }}$ by a common noun like CHILD in this same context yields a specific meaning of the noun phrase, that is, it refers to a particular child and the determiner is associated with a low locus. Crucially, the sign CHILD is signed at a low locus. ${ }^{3}$

(29) IF ONE up PERSON $_{\text {up }}$ REPLIES BAD, ELIMINATE. (video)

'If someone (of the players) gives an incorrect answer, he/she is out.'

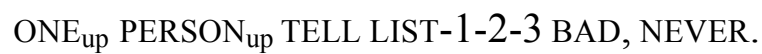

'One never realises of his own bad habits.'

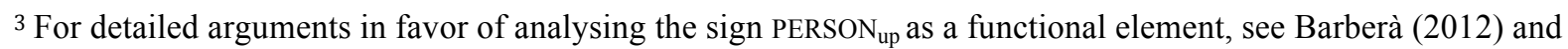
Pfau \& Steinbach (2013).
} 
Interestingly, in corporate contexts, which include designated subjects (Kärde 1943, Pesetsky 1995), the meaning of PERSON ${ }_{\text {up }}+++$ and $\mathrm{ONE}_{\text {up }}$ PERSON $_{\text {up }}$ triggers different readings depending on the type of predicate they occur with. With predicates that include a strong implicature that the subject is of a particular type, as in "raise the taxes", both PERSON $\mathrm{UP}^{+++}$and $\mathrm{ONE}_{\mathrm{up}}$ PERSON $_{\text {up }}$ trigger a corporate meaning with the implicature that a particular person in charge is responsible for that. When PERSON $\mathrm{up}^{+++}$is used, the subject associated to the predicate cannot be paraphrased as "someone" or "people in general", and it triggers the implicature of "the particular people at the ministry in charge of it". When $\mathrm{ONE}_{\text {up }}$ PERSON$_{\text {up }}$ is used, the implicature that it is precisely the former Minister of Finances (Montoro, in Spain in 2017) is strongly raised.

(31) a. PERSON $\mathrm{up}+++$ TAXES RAISE.

'They raised the taxes.'

$\rightarrow$ corporate meaning: the particular people working at the ministry being in charge of it

b. ONE $_{\text {up }}$ PERSON up TAXES RAISE.

'One person (namely Montoro) raised the taxes.'

$\rightarrow$ corporate and specific meaning

However, this is not the case with corporate contexts involving a predicate where the implicature is not raised so strongly. The predicate "take the second-hand clothes" gives rise to a corporate meaning when featuring a null pronoun (32a). Yet, when a lexical subject is used, such as PERSON ${ }_{\text {up }}+++$ and $\mathrm{ONE}_{\text {up }}$ PERSON $_{\text {up }}$, the sentence may be ambiguous between a corporate meaning and an unrestricted meaning (32b, 32c). Therefore, the readings may possibly vary depending on the kind of predicate, rather than on the kind of impersonal context. Note that this holds not only for episodic uses of corporate readings, as shown in (32), but also in generic uses of corporate, such as 'Here they deliver the mail at 8am'.

(32) a. CLOTHES SECOND HAND TAKE 3 up ${ }^{++}$.

'They took away the second-hand clothes.'

$\rightarrow$ corporate meaning

b. PERSON up $^{+++}$CLOTHES SECOND HAND TAKE 3 up ++ .

a. 'They (people from the enterprise) took away the second-hand clothes.'

$\rightarrow$ corporate meaning

b. 'They (people in general) took away the second-hand clothes.'

$\rightarrow$ unrestricted meaning

c. $\mathrm{ONE}_{\text {up }}$ PERSON $_{\text {up }}$ CLOTHES SECOND HAND TAKE 3 up ++ .

a. Someone (from the enterprise) took away the second-hand clothes.'

$\rightarrow$ corporate meaning 
b. Someone (in general) took away the second-hand clothes.'

$\rightarrow$ unrestricted meaning

In anchored existential contexts and inferred contexts, when the determiner and generalised noun $\mathrm{ONE}_{\text {up }}$ PERSON $\mathrm{up}_{\text {up }}$ is used, an evidential reading arises. The sentence is only felicitous if the person talked about has been seen, although not recognised. These cases are illustrated in (33) and (34).

HEY ONE up PERSON up IX-LOC KNOCK IX-LOC.

'Hey! One person (I have seen but I don't know) is knocking on the door.'

$\mathrm{ONE}_{\text {up }}$ PERSON $_{\text {up }} \mathrm{TOUCH}_{\mathrm{c}}$ ALREADY.

'Someone (I have seen from far away) has already touched it.'

Finally, according to our informants, a different order of the determiner and the generalised noun does not convey a different meaning (in contrast with Italian Sign Language, in which the order is relevant, see Mantovan 2017). The determiner in both a prenominal and postnominal position gives rise to the same non-specific and unknown meaning, as long as it is associated with a high locus and co-occurs with the particular non-manuals associated with epistemicity (which include sucking the cheeks in and pulling the mouth ends down, sometimes combined with a shrug). In some contexts, the determiner, besides being associated with a high locus, may also have a tremoring movement.

$\mathrm{ONE}_{\text {up }}$ PERSON $_{\text {up }} /$ PERSON $_{\text {up }}$ ONE $_{\text {up MOMENT PREGNANCY BEGIN, ALWAYS THROW UP. }}$

'When someone is at the beginning of her pregnancy, always throws up.'

\section{Conclusions}

Extending on previous work, this paper has focused on four types of agent-backgrounding strategies in LSC and has described the semantico-pragmatic properties of each construction. First, in the high locus construction an empty subject combines with an agreement verb that shows agreement with an empty locus in a high location. It is a transitive construction and the null subject can therefore be analysed as an R-impersonal strategy. Second, the two indefinite pronouns, $\mathrm{WHO}^{\wedge} \mathrm{SOME}_{\mathrm{up}}$ and $\mathrm{ONE}_{\mathrm{up}}$, may be found in most of the impersonal contexts, but they differ with respect to their specificity profile: while both are epistemically non-specific, $\mathrm{ONE}_{\mathrm{up}}$ is interpreted as scopally and partitively specific, while $\mathrm{WHO}^{\wedge} \mathrm{SOME}_{\text {up }}$ is neutral with respect to scopal and partitive specificity. Third, the impersonal axis marks the lack of referential encoding of the discourse referents through locations established in signing space by means of 
agreeing verbs. The axis goes from a spatial location established between $1^{\text {st }}$ and $3^{\text {rd }}$ person to a location established between $2^{\text {nd }}$ and $3^{\text {rd }}$ person location. In the impersonal axis structure both arguments of the verb are two non-specified arguments and this is marked in the diagonal movement path of the agreeing verb, in the initial and final locations, and in the particular non-manual marking associated with it. Last but not least, lexical subjects are another frequent strategy when conveying agent-backgrounding. Here we have focused on two different constructions signalled by two different lexical elements: on the one hand, the generalised noun PERSON $\mathrm{up}+++$ articulated as the reduplication of the sign PERSON localised in a high locus; and on the other, the noun phrase formed by the indefinite determiner $\mathrm{ONE}_{\mathrm{up}}$ and the generalised noun PERSON ${ }_{\text {up }}$ in its singular form, both associated with a high locus. The main difference between the two forms is that the use of $\mathrm{ONE}_{\mathrm{up}}$ PERSON $_{\mathrm{up}}$ in corporate contexts triggers a specific meaning for the referent, while this is not the case with PERSON $_{\mathrm{up}}+++$, where a corporate meaning is conveyed.

\section{Acknowledgments}

This work was partly supported by the Franco-German ANR-DFG project 'Towards a typology of human impersonal pronoun' (ANR-11-FRAL-0011, 2012-15); the SIGN-HUB project, which has received funding from the European Union's Horizon 2020 research and innovation program under grant agreement No 693349; the Spanish Ministry of Economy and Competitiveness and FEDER Funds (FFI2015-68594-P); and the Government of the Generalitat de Catalunya (2017 SGR 01478). We are grateful to Delfina Aliaga and Santiago Frigola for their contribution in the elicitation sessions and for the fruitful discussions of the LSC examples. All remaining mistakes are our responsibility.

\section{References}

Barberà, Gemma. 2012. The meaning of space in Catalan Sign Language (LSC). Reference, specificity and structure in signed discourse. Barcelona: Pompeu Fabra University dissertation [published as monograph in 2015, Berlin \& Nijmegen: De Gruyter Mouton \& Ishara Press].

Barberà, Gemma. 2016. Indefiniteness and specificity marking in Catalan Sign Language (LSC). Sign Language \& Linguistics 19(1). 1-36.

Barberà, Gemma \& Patricia Cabredo Hofherr. 2017a. Backgrounded agents in Catalan Sign Language (LSC): passives, middles, or impersonals? Language 93(4). 767-798.

Barberà, Gemma \& Patricia Cabredo Hofherr. 2017b. Two indefinite pronouns in Catalan Sign Language (LSC). Proceedings of Sinn und Bedeutung 21. 89-105. 
Barberà, Gemma \& Brendan Costello. 2017. ¿Cómo se expresa la referencia impersonal? Análisis contrastivo entre lengua de signos catalana (LSC) y lengua de signos española (LSE). Actas del Congreso CNLSE de la Lengua de Signos Española: Madrid, 24 y 25 de septiembre de 2015, 49-63. Madrid: Real Patronato sobre Discapacidad.

Barberà, Gemma \& Josep Quer. 2013. Impersonal reference in Catalan Sign Language (LSC). In Laurence Meurant, Aurélie Sinte, Mieke van Herreweghe \& Myriam Vermeerbergen (eds.), Sign Language Research Uses and Practices: Crossing Views on Theoretical and Applied Sign Language Linguistics, 237-258. Berlin/Boston: De Gruyter Mouton \& Ishara Press.

Costello, Brendan. 2015. How do you/we/they get impersonal in Spanish Sign Language (LSE)? A first look. Paper presented at the Workshop Langues des signes et $R$ Impersonnels. 6 February 2015, UMR7023 CNRS\&Université Paris-8.

Farkas, Donka. 2002. Specificity distinctions. Journal of Semantics 19. 1-31.

Heusinger, Klaus von. 2002. Specificity and definiteness in sentence and discourse structure. Journal of Semantics 19. 245-274.

Kärde, Sven. 1943. Quelques manières d'exprimer l'idée d'un sujet indéterminé ou général en Espagnol. Uppsala : Appelbergs Boktryckeriaktiebolag.

Keenan, Ed and Matthew S. Dryer. 2007. Passive in the world's languages. In Timothy Shopen (ed.), Clause structure, language typology and syntactic description, Vol. 1, 325-361. Cambridge: Cambridge University Press.

Kelepir, Meltem, Aslı Özkul \& Elvan Tamyürek Özparlak. This volume. Agentbackgrounding in Turkish Sign Language (TID).

Mantovan, Lara. 2017. Nominal modification in Italian Sign Language (LIS). Berlin: De Gruyter Mouton.

Matthewson, Lisa. 2004. On the Methodology of Semantic Fieldwork. International Journal of American Linguistics 70. 369-415.

Pesetsky, David. 1995. Zero Syntax. Cambridge, MA : MIT Press.

Pfau, Roland \& Markus Steinbach. 2013. PERSON climbing up a tree (and other adventures in sign language grammaticalization). Sign Language \& Linguistics 16(2). 189-221.

Corresponding author's address

Gemma Barberà

Universitat Pompeu Fabra

Roc Boronat, 138

08018 Barcelona, Spain

https://gemmabarbera.wordpress.com 
gemma.barbera@upf.edu 